CRITICAL ASSESSMENT OF THE RECENT CHANGES TO THE POINT SYSTEM AND CANADIAN EMPLOYERS' HIRING PRACTICES

$$
\text { by }
$$

Deanna Ida, BA, Brock University, 2010

\author{
A Major Research Paper \\ Presented to Ryerson University \\ in partial fulfillment of the requirements for the degree of \\ Master of Arts \\ in the Program of \\ Immigration and Settlement Studies
}

Toronto, Ontario, Canada, 2013

(C) Deanna Ida 2013 


\section{AUTHOR'S DECLARATION FOR ELECTRONIC SUBMISSION OF A MAJOR RESEARCH PAPER (MRP)}

I hereby declare that I am the sole author of this MRP. This is a true copy of the MRP, including any required final revisions.

I authorize Ryerson University to lend this MRP to other institutions or individuals for the purpose of scholarly research

I further authorize Ryerson University to reproduce this MRP by photocopying or by other means, in total or in part, at the request of other institutions or individuals for the purpose of scholarly research.

I understand that my MRP may be electronically available to the public.

Deanna Ida. 


\title{
CRITICAL EXAMINATION OF THE RECENT CHANGES TO THE POINT SYSTEM AND CANADIAN EMPLOYERS' ASSESSMENT PRACTICES
}

Deanna Ida

Master of Arts 2013

Immigration and Settlement Studies

Ryerson University

\begin{abstract}
The recent changes to the Canadian Point System in relation to the Federal Skilled Worker Program (FSWP) have greatly impacted the types of applicants that will be admitted to Canada. Through a Critical Discourse Analysis (CDA), it is my intention to explore the hiring practices of some Canadian employers and how immigrants currently fare in the labour market. A CDA will also be conducted based on the adjustments to the point distribution of specific selection factors for the FSWP. Because the most recent changes to the Point System were made in May 2013, this MRP will be one of the first if not the first to critically assess the May 4, 2013 changes to the Point System from a rights-based perspective. I will also explore whether or not the Government takes responsibility for helping immigrants facing discrimination in the labour market. Finally, I will investigate whether the adjustments to the Point System reinforces and legitimates the discriminatory practices of some Canadian employers.
\end{abstract}

Key Words: Point System, discrimination, Canadian employers 


\section{ACKNOWLEDGEMENTS}

I would first like to thank my MRP supervisor Dr. Anver Saloojee for agreeing to be my supervisor. I was fortunate enough to have him as a professor, where he enlightened my views and has provided me with the most insightful guidance I could have asked for, during my MRP writing experience. I would like to thank my second reader Dr. Amina Jamal, who I am fortunate enough to have worked for, as a Research Assistant. During my time at Ryerson University, both Dr. Saloojee and Dr. Jamal have been two scholars who have greatly inspired me.

I would also like to thank my family for believing in me, especially my sister and my best friend Antonio for their unconditional support, without them this would not have been possible. 


\section{TABLE OF CONTENTS}

Introduction 1

Section I: Literature Review and Methodology 3

Section II: The Evolution of the Point System 22

Section III: The Point System Failures and Successes 26

Section IV: The Recent Adjustments to the Point System, Reflecting

Discriminatory Practices? 32

Section V: The Adjustments to the Point System Undermines Canada's

Constitution $\quad 50$

Section VI: Policy Recommendations

Conclusion $\quad 54$

References $\quad 56$

TABLES

Table 1 The Evolution of the Canadian Point System (1967) 24

$\begin{array}{ll}\text { Table } 2 \text { Point Changes } & 38\end{array}$

Table 3 Point Changes for Experience Factor 44

GRAPH

Graph Average employment earnings (2005\$) for skilled principal

applicants by landing year and tax year, 1981 - 2005 


\section{Introduction}

The immigration process plays an integral role in the socio-economic development of immigrant accepting countries. Migrants settle in a new country for a variety of complex push and pull factors and other circumstances, - whether it is to escape undesirable living conditions and/or further self-development. It is important to understand how immigrants integrate into their host countries in this case Canada, through various mechanisms. Canada has a global reputation of being recognized as a multicultural society. All immigrants despite their ethnic and cultural backgrounds should expect to find support equally in their integration efforts through the Canadian system, whether it is through settlement agencies or occupational opportunities.

Financial well-being is an essential prerequisite for survival in contemporary market based economies. Therefore, it is imperative that there be fair and equitable access to the labour market and that labour market integration be free of discriminatory barriers. There is a considerable body of research regarding immigrants and the labour market that deals with discriminatory practices based on language fluency, foreign names, foreign experience and foreign acquired credentials (Alboim et al., 2005; Grenier \& Xue, 2011; Li, 2003; Oreopoulos, 2009). It will be argued that labour market discrimination can be connected to the Federal Skilled Worker Program (FSWP) stream of the Immigration Policy because success rates for immigrants in the labour market depends on a number of criteria such as language fluency, experience, education, adaptability and age, which are all selection factors for FSWP's Point System. Recent reforms to the Canadian Point System indicate points will be distributed differently - these changes will be discussed in more detail below (CIC, 2013g). The focus of the analysis will be on the May 4, 2013 changes to 
the Federal Skilled Worker Program (FSWP) of the economic class, and the main subjects of the literature will be highly skilled immigrants.

As Canada continues to restructure the immigration system and in particular the Point System, the question that arises is whether, through these changes, the Canadian state is reinforcing and reproducing some of the current discriminatory practices, attitudes and stereotypes towards immigrants' foreign acquired education, work experience, and skills extant in the Canadian labour market? This study will attempt to answer this important research question by exploring the evolution of the Point System, analyzing the current literature based on immigrant's success or lack thereof in labour markets, and critically examining the May 4, 2013 changes to the Point System.

Many studies on labour market integration of immigrants in Canada have examined the obstacles faced by immigrants from non-English and non-French speaking countries when trying to gain employment in their trained profession. Job searches often result in many of these immigrants being either unemployed or underemployed.

State policies to date, have not adequately addressed these issues because they have largely focused on tailoring the Point System to select applicants who meet specific labour market criteria. Historically, Canada was a white settler colonial society, which has privileged immigrants based on race, gender, class, sexuality, religion and ethnicity ( $\mathrm{Li}, 2003)$. It is quite possible that various iterations of the of the Immigration Policy over the decades including significant changes to the Point System continue to be informed by the colonial culturist construct leading to discriminatory effects for FSWP applicants. Over the past decade or more the Canadian Point System has been altered to attract applicants with previous Canadian 
experience who could easily assimilate into the labour markets and may not experience the barriers to the workplace integration affecting those who come from non-English and non-French speaking countries. The changes in the Point System are problematic as cumulatively they reflect the discriminatory assessment practices of some Canadian employers as well as some self-regulating bodies. In this paper it will be argued that the recent adjustments of May 4, 2013 result in the reproduction of systemic barriers to labour market integration of immigrants from non-English and non-French speaking countries. These changes to the new Point System call into question Canada's commitment to Multiculturalism and human rights enshrined in the Charter of Rights and Freedoms.

This MRP is the first to apply a Critical Discourse Analysis (CDA) to assess the implications of the new distribution of points. The paper will be divided into six sections and a conclusion. The Literature Review and the Methodology will be in Section I. Section II will detail the evolution of the Point System; Section III will assess both the successes and the challenges of the Point System. Section IV will critically analyze how the changes to the Point System over time have sought to address Canadian Labour Market needs while simultaneously discounting the credentials and skills of foreign workers. Section V will assess whether recent changes to the Point System violate the central tenets of The Multicultural Act and The Canadian Charter of Rights and Freedoms. Section VI will identify policy recommendations designed to address the inequities identified in the Point System.

\section{Section I: Literature Review and Methodology}

Presently, there is little literature that directly answers the research question posed: As Canada continues to restructure the immigration system and in particular the Point System, is the Canadian state reinforcing and reproducing some of the 
current discriminatory practices, attitudes and stereotypes towards immigrants' foreign acquired education, work experience, and skills extant in the Canadian labour market? And there is no literature that looks at the implications of the May 2013 changes to the Point System. However, research dealing with the highly skilled immigrants attempting to enter the Canadian labour market as well as studies focusing on Canadian employers' assessment practices targeting immigrants' qualities and attributes will both be useful starting points for research. While there is no current scholarly work on the most recent changes of the Point System that took effect on May 4, 2013, the literature discussing the historical background and evolution of the Point System will be helpful in conducting the analysis. The literature review is divided into the following four subsections: (a) The Canadian Labour Market, Skilled Immigrants and Employers' Practices, (b) The Point System, Immigration Policy and Constitution, (c) Common Themes and (d) Literature Gaps.

\section{(a) The Canadian Labour Market, Skilled Immigrants and Employers'}

\section{Practices:}

The first part of this literature review deals with articles regarding the discrimination that some skilled immigrants are faced with and with the practices of some employers in the Canadian labour market.

The name of an applicant featured on a resume can have a negative impact on whether or not the resume will even be assessed. This is not just an issue related to newcomers but Canadian born immigrants with ethnic sounding names can also face the same problem. In a study conducted by Oreopoulos (2009) thousands of resumes were distributed in Toronto for multiple occupations for the purpose of determining the reasons why Canadian immigrants who, despite the fact that they were allowed entry based on their skills, still face difficulties in accessing employment. Oreopoulos 
outlines the ineffectiveness of policies and programs designed to help immigrants (2009). He explains that in the United States recent immigrants experience a disadvantage in the labour market and this also happens in Canada even though “[Canada's] immigration policy focuses on attracting immigrants with superior levels of education, experience, and the industry demand to offset an anticipated skilled labour force shortage and encourage economic growth" (Oreopoulos, 2009, 6). Based on his findings he concludes these programs, which help with integration seem almost pointless as immigrants continue to face many barriers to job attainment, despite education and experience (Oreopoulos, 2009). His conclusion is relevant to the research question, as he indicates that the current immigration policy and implemented programs do not address barriers much like the recent changes to the Point System.

Oreopoulos focuses his study on names, which appear on the resume. Despite certain limitations, the name on a resume can be an indication that someone is foreign and not accustomed to organizational norms, language proficiency and non-Canadian experience. The study found that that resumes are disregarded simply on the basis of name despite the fact there is a possibility that the resume with a foreign name belongs to someone more qualified than the job seeker who happens to have a resume with an English sounding name. It is not possible for someone to participate equally in the Canadian labour market and in Canadian society if they are being discriminated on the basis of the "foreignness" of their name. Oreopoulos uses English-sounding names and foreign-sounding names of Chinese, Indian and Pakistani descent to illustrate the difference of selection based on name (2009). Oreopoulos states, "a number of researchers suggest that the conditions by which employers sort through resumes make it more likely that name discrimination is unintentional" $(2009,42)$. 
Canadian employers may deal with large piles of resumes and selection can be simplified by eliminating resumes with the most foreign names and work experiences: "employers statistically discriminate by name and location of experience because they believe these characteristics signal a greater chance of inadequate language and cultural skills for the job" (Oreopoulos, 2009, 40).

Oreopoulos concludes "employers discriminate substantially by the name provided on the resume. More specifically, employer contact falls 40 percent when switching from a Canadian resume with a common English name to one with a common Indian, Chinese, or Pakistani name" $(2009,40)$. If immigrants cannot get past the screening of resumes based on name, this automatically closes the door to workplace diversity. Canadian employers need to look beyond the name in order to properly assess the applicant's capabilities. Oreopoulos' study pertains to the research question, as it is indicative of Canadian employer's practices when examining resumes and Canadian employers constitute one of the first gatekeepers to labour market entry for new immigrants seeking employment.

The disregard of foreign acquired credentials does not help immigrants socially and economically advance in Canadian society. The study by Shinnaoui and Narchal (2010) explores the discounting of foreign credentials. The authors have several hypotheses, and explore the idea, that immigrants from culturally and linguistically diverse (CALD) communities are not valued as much as immigrants from English speaking backgrounds (ESB) (Shinnaoui and Narchal, 2010). Even though this study is conducted in Australia, it uncovers discriminatory practices that are also relevant in the Canadian context. Their study was modeled on a previous Australian study conducted by Esses et al., and both studies yielded similar results. Shinnaoui and Narchal's methodology utilizes student participants who are told to 
rate resumes on the basis of person-job fit and person-organization fit (Shinnaoui and Narchal, 2010). Their findings support the hypothesis that CALD background resumes rate significantly lower than those resumes of Australian and ESBs. The CALD resumes consisted of credentials and training received in Lebanon, while ESB resumes consisted of credentials from the United Kingdom. Shinnaoui and Narchal find, "regardless of the existence of migration policies in nations like Australia that are designed to safeguard the economic prosperity of skilled migrants... [they] demonstrate subtle biases in perception of person-job fit, and person-organization fit of migrant job applicants resulting in the discounting of a migrant's foreign acquired credentials" (2010, 432). Shinnaoui and Narchal's study exposes controversial practices used by employers when evaluating foreign credentials.

This study is relevant to the research question as Australia and Canada depend on immigrants for population growth and economic stability yet some employers in both countries do not properly assess candidates with foreign acquired credentials. As Shinnaoui and Narchal note, "migrants advance the economic development of host nations such as substantiating labour shortages, investing in host economy, and enhancing international trade through awareness of overseas markets" $(2010,424)$. It seems that there should be more effort in ensuring that immigrants are being fairly assessed when it comes to the application processes. If immigrants are being turned away because their background is not English or French this is a form of discrimination that violates the equality provisions of both the Canadian Charter of Rights and Freedoms and Human Rights legislation, which provide for equal access to the Canadian labour market.

Foreign experience often has less value placed on it when compared to Canadian experience, as highlighted in a number of studies. A study conducted by 
Alboim et al. (2005) explores whether or not non-Western degrees and non-Western experience are valued in Canada. Their methodology is based on empirical analysis, utilizing the Statistics Canada's Survey of Literacy Skills Used in Daily Activities (LSUDA) database to shed light on the link of literacy and income plus other areas (Alboim et. al., 2005). With respect to occupational competencies, the authors note:

Canadian employers tend to use previous work experience and references as a proxy for demonstrated skills and competencies. When they are not familiar with the names or functions of the employing organizations and cannot easily get references they trust, they may be reluctant to take a chance on the individual's work experience was obtained outside Canada (Alboim et al., 2005, 18).

The authors' findings allow them to conclude that immigrants' foreign degrees are discounted in the Canadian labour market (Alboim et al., 2005). Alboim et al. suggest they cannot precisely explain why non-white immigrants with foreign education do not do as well, but they suspect that it has something to do with the inability of Canadian employers to properly assess the value of foreign degrees.

Grenier and Xue (2011), conducted a study over a four-year period where they monitored immigrants' progress and their ability to obtain the occupation, for which they are trained for and experienced in. The authors discovered that immigrants with Canadian experience tended to land their "intended" occupations at a faster rate than immigrants with only foreign work experience. The authors use the word "intended" (Grenier \& Xue, 2011) in the context, of an occupation the immigrant is trained for and experienced in as they intend to be employed for the same occupation in Canada.

Grenier and Xue (2011) estimate the length of time required before an immigrant attains their "intended" (2011) occupation upon arrival in Canada. Towards this end, they use various explanatory variables such as human capital, Canadian experience, immigration category, socio-demographic characteristics, social capital, skill level and transferability along with information based on employment 
trajectory provided by Longitudinal Survey of Immigrants to Canada (LSIC) (Grenier \& Xue, 2011).

According to their findings, Canadian experience is valued over foreign experience, which is consistent with Shinnaoui and Narchal's conclusions. Grenier and Xue's main finding is that the first year of arrival is the most critical year for immigrants in obtaining the "intended" occupation (Grenier \& Xue, 2011). However, they find the challenge of attaining the "intended" occupation begin to decrease with more time spent in Canada (Grenier \& Xue, 2011, 298), possibly because immigrants gain Canadian experience over time in other occupational sectors, their language skills may improve and they may now be assimilated to Canadian society.

It is no surprise that immigrants who intend working in non-professional occupations quickly obtain their first job upon arrival. Grenier and Xue also find that immigrants who may end up in professional occupations may take approximately five years or more to do so (2011).

Grenier \& Xue's research is valuable to the research question in this paper, as it shows the value of Canadian experience when seeking a job in the Canadian labour market and also indicates the time-frame within which an immigrant generally obtains an "intended" occupation. However, the authors briefly mention that the "intended" jobs do change over time. This observation has significant bearing as it can potentially skew the results of the whole study. If other jobs over time become more desirable than the "intended" occupations, this implies that the "intended" jobs might be abandoned and the independent variables will not carry much weight. For example, the "intended" occupation can be a lawyer but the actual job attained by choice is a human resource worker. This result potentially invalidates all the independent variables since the actual job attained is in a completely different area of employment. 
Grenier and Xue explain, "human capital including education, language skills, and pre-migration Canadian experience are important factors determining the occupational outcomes of recent immigrants, while foreign work experience does not have a significant effect on access to the intended occupation" $(2011,277)$. Their conclusions indicate that it is essential to ensure that immigrants can properly integrate into the Canadian labour market at a faster rate. This study is also relevant to the research question, as Canadian employers need to reevaluate foreign experience, as these skilled immigrants gained permanent residency through areas that involve valuable experience under the Point System. It is significant to consider that foreign experience may possibly be more significant than that acquired in Canadian experience, which is why the discrediting practice is unfair.

Kareem D. Sadiq a research officer of the Department of Canadian Heritage for Multiculturalism and Human Rights Branch (Sadiq, 2005) also addresses the issue of foreign credential recognition. Sadiq quotes Reitz who suggests, "that the reduced value of work owing to the non- recognition of immigrant credentials in Canadian workplaces amounts to over \$2 billion annually" (Reitz cited by Sadiq, 2005, 63). This considerable financial loss is based on the limited recognition of foreign credentials. Sadiq argues that the insufficient appreciation of foreign credentials in comparison to Canadian attained credentials is reflective of a "discriminatory bias" (2005, 63). This form of discrimination can only be detrimental to Canada's multicultural nature because immigrants are not getting jobs because of their racial differences. It also represents a significant loss to the individual and to the revenues of the state. Sadiq's article indicates that there is an essential need to shift the focus away from the selection of immigrants at entrance and towards the direct support of immigrants to integrate into the labour market. 
Canada's policy of multiculturalism as expressed in the Multiculturalism Act Section 3(1)(f) stresses the importance of ethnic language acceptance and preservation: "preserve and enhance the use of languages other than English and French" (CMA, 1985). Canadian workplaces should be institutions that value immigrants' linguistic differences, whether it is an accent or speaking English/French as an additional language. Sadiq explains, "accent is a marker of cultural and ethnic difference, an indicator that one may not have the skills to perform the job. In as much as 'closer screening' can be utilized to evaluate an immigrant candidate's language skills, discriminatory attitudes towards accent call into question his or her fit with an organization" (Sadiq, 2005, 63).

Similarly, Munro notes that, "a person may react negatively to an accent for a variety of reasons. One possibility is that the prejudices one holds against a particular group of people may be activated when one hears speech patterns associated with that group" $(2003,39)$. These attitudes are an indication that highly skilled workers are not being judged properly in the workplace and their accents and languages are preventing them from reaching a fair level in the work place.

Mirchandani (2004) analyzes a case study featured in the Toronto Star, which indicates that employers discount foreign skills. Mirchandani lists possible solutions for labour market to improve for immigrant workers: "provide better integration and settlement programs. Examples include better language training, internship programs for new immigrants, and job search programs" (Mirchandani, 2004). Mirchandani analyses the case of Gulraj Rijhwani and his family. Their story is featured in the Toronto Star (2002). In India, Rijhwani had 25 years of experience in pharmaceuticals and his wife Geeta has worked 17 years as a bank teller (Mirchandani, 2004): 
In the months after their arrival, the Rijhwanis sent out more than 1000 resumes in an effort to secure jobs. They searched for information on their professions on the web and emailed former classmates now living in North America for advice. They registered with employment agencies. They attended job orientation seminars where they were taught how to 'sound less like foreigners' and applied for minimum-wage jobs in order to gain local experience. (Mirchandani, 2004, 63).

This excerpt emphasizes the struggle that not only Rijhwani and his family face but other immigrants may confront when they first settle in Canada. The Rijhwanis feel the need to attend classes in order to learn how to properly assimilate and how to sound less foreign. These cultural differences should be celebrated in a multicultural society, but the reality is the longer it takes for an immigrant to lose their foreign attributes the more difficult it becomes to secure a job and integrate. The Rijhwanis family felt discouraged and even contemplated returning to their home in India. Two members of the family experienced underemployment and employers trying to take advantage of their newcomer vulnerability.

Mirchandani explains that after an 8 hour shift, Rijhwani was asked to perform another 8 hour shift because a co-worker called in sick, Rijhwani refused and his boss told him not to return (2004). His wife was told at her work place, a jewelry store, that she would have to train without pay for two months (Mirchandani, 2004). Eventually after an extended struggle both were able to accumulate Canadian experience. They were able to attain the occupations for which they were trained for and for which they had prior experience. Their accumulated Canadian experience relates to the Grenier and Xue's study as Canadian experience allows immigrants to obtain their "intended" job over time.

There are earning differentials for some Canadian-born visible minorities as they earn less than the rest of Canadians. Pendakur and Pendakur, in their study find that the earning gaps for Canadian- born visible minorities from the 1990s has not 
“eroded": "In the context of rapidly growing 'home grown' minority populations, one might expect that ethically based gaps in the labour market performance would diminish over time. We find, to our chagrin, that earnings gaps between white and visible minority workers, which first widened in the 1990s, remain very large" (2011, 305-306). This indicates that settlement in the labour market for visible minority immigrants would also continue to be a problem, even after the first stages of migration, as even Canadian- born visible minorities are faced with earning gaps. For Pendakur and Pendakur, even if a member of a minority group is socialized and educated in Canada with language proficiency in either official language, their earnings are still lower than a "white worker". This shows racial discrimination is still a salient issue in the Canadian labour market, where visible minorities are earning less than someone who is white and in most cases male.

In another study conducted by Pendakur and Pendakur, minority languages are associated with lower earning power. In the three largest cities in Canada, the authors found that minority languages, for men and women, correlates with lower earnings (2002). They argue, "minority ethnicity- and the discrimination associated with itmay be a layered phenomenon. We find that members of ethnic minorities who speak their language tend to fare worse in labour markets than members of those same minorities who do not" (Pendakur and Pendakur, 2007, 173). Their research suggests that there are less points being allocated for bilingualism, which appears to be undervalued in the Point System.

Reitz (2005) deals with the concept of underutilization. His study examines the declining job availability as immigrants' skills are being underutilized and this is viewed as an economic loss for Canada. Reitz also identifies institutional problems 
that must be confronted in order to change the way highly skilled immigrants are treated in society in order to maximize their skills.

\section{(b) The Point System and Immigration Policy:}

This part of the literature review deals with sources based on the Point System and the Immigration Policy. Alboim and Cohl describe the impact of changes to the Immigration Policy between 2008 and July 1, 2012 (2012). In their paper they investigate the proposed changes and analyze their impacts on Canadian society and future. The authors conclude that some of the changes will negatively impact Canada, as these changes reflect the short-term needs of the labour market and an overall "less welcoming environment" for potential immigrants and refugees. Alboim and Cohl's article is pertinent to the following analysis, as this paper deals with similar concerns critically analyzing the actual changes made to the Point System on May 4, 2013.

Green and Green (1995) specifically focus on the introduction of the 1967 Point System. Their article is useful in understanding why the Point System came into effect. Green and Green's 1999 study is also useful as the authors examine the economic goals of the Point System. They argue that immigration cannot be used to control the economy, and they do not believe that immigration is the best tool for fulfilling economic goals. Instead they argue that immigration needs to focus on humanitarian issues, which presently is not the case with all the new regulations in place. They provide a useful chart to track the major changes in the Point System. This chart is reproduced and updated in the analysis below.

Lowe (2010) touches on important issues concerning recent shifts in the immigration policy. She explains the importance of nation builders in relation to temporary workers and concludes that the policy has shifted in response to problems 
in the labour market, but these changes do not suffice, as they do not solve the issues of discrimination, unemployment and underemployment.

The recent Point System adjustments were officially released on May $4^{\text {th }}$, 2013, and there is no current literature on these changes. My focus is to provide the first Critical Discourse Analysis on these adjustments. The Citizenship and Immigration Canada (CIC) website will be used to obtain specific information on the changes along with CIC news releases.

\section{(c) Common Themes:}

This part of the literature review indicates the common themes found in the literature. There are a number of recurring themes identified in the literature. These themes include discrimination and the barriers immigrants face, particularly those with notable physical differences, language fluency, accents, the discrediting of foreign acquired skills, discrepancies in earnings between immigrants and Canadian born citizens, rates of unemployment and underemployment and lack of integration into the labour market and society. The latter leads to poor networks in the labour market. These common themes will provide a starting point for conducting the Critical Discourse Analysis, which will be used to answer the research question.

\section{(d) Literature Gaps:}

Finally, this part of the literature review identifies the literature gaps. It was challenging to find literature based solely on the Canadian Point System and the recent changes to the Point System. There are currently no published scholarly articles that analyze the new point distribution, which is the primary focus of this paper. As mentioned, there was no research conducted on the research question: As Canada continues to restructure the immigration system and in particular the Point System, a critical question arises: is the Canadian state reinforcing and reproducing some of the 
current discriminatory practices, attitudes and stereotypes towards immigrants' foreign acquired education, work experience, and skills extant in the Canadian labour market? The existing literature limited as it is, will be linked with the information of the recent Point System changes found on Citizenship and Immigration Canada's website to provide a comprehensive analysis that answers the research question.

\section{Methodology}

It is important for researchers to identify their methodological options and consider any ethical concerns before performing research. Methodology can be defined as a description of methods used to collect and analyze data (Archer \& Berdahl, 2011). Research for this paper did not involve any human subjects, so there are no ethical considerations with respect to human subjects. As stated, the focus of the paper is on highly skilled immigrants with education in professional fields entering Canada via the Federal Skilled Workers Program (FSWP). There is an abundance of research regarding immigrants and their experience in the Canadian labour market. The literature tends to highlight common themes that involve discriminatory practices based on language fluency, foreign names, foreign experience and foreign acquired credentials.

Theoretical perspectives provide a lens through which one can examine and gain a better understanding of data. Archer and Berdahl explain, "a theory identifies a general pattern of behavior" $(2011,31)$. The theoretical perspectives that will be utilized in the research are aversive racism theory (ART), critical race theory (CRT) and muted group theory (MGT). The recent Point System adjustments will be analyzed through a critical discourse analysis (CDA).

CRT applies critical examination through the intersection of law, race and power prevalent in society and culture (Gilborn, 2006). CRT recognizes that white 
privilege is predominant in power structures and it continues to marginalize nonwhites. CRT highlights the concept of institutional racism. Gilborn quotes MacPherson, as follows:

"Institutional Racism" consists of the collective failure of an organization to provide an appropriate and professional service to people because of their colour, culture, or ethnic origin. It can be seen or detected in processes, attitudes and behaviour which amount to discrimination through unwitting prejudice, ignorance, thoughtlessness and racist stereotyping which disadvantage minority ethnic people $(2006,21)$.

This theory will be utilized to analyze the changes of the Point System, as these adjustments may potentially reduce applications from certain geographic regions. The common critique of this theory is that it relies on narrative and storytelling (Gilborn, 2006).

Aversive racism a theory first proposed in 1986 by Gaertner and Dovidio, illustrates the negative evaluations of racial and ethic minorities by the dominant (white) group (Gaertner and Dovidio, 2004). The framework of this theory highlights the conflict between white persons denying practices of prejudice and unconscious negative thoughts towards minority groups (Gaertner and Dovidio, 2004).

Gaertner and Dovidio (2004) discovered their theory was coherent and that applicants who were clearly qualified for a position over another applicant always received the role without any regard to cultural differences (Gaertner and Dovidio, 2004). However, when both candidates had the equivalent experience, the white applicant was always chosen over the non-white applicant. This experiment was conducted in both 1989 and 1999, and yielded the same results. The authors conclude that, "aversive racism may be one factor that contributes to disparities in the workplace and their [non-whites] performance in it" $(2004,1)$. ART supports the notion that prejudice is formulated by regular cognitive processes, which leads to biases toward others (Shinnaoui and Narchal, 2010). This theory will be used with 
analyzing the literature related to discrimination that some immigrants face in the Canadian labour market. The critique of the ART is that it is subjective. This means it may lack rigor and it makes sense intuitively but is hard to measure and test on an empirical level.

MGT involves "people with little power who have trouble giving voice to their perspectives because they must re-encode their thoughts to make them understood in the public sphere" (Griffin, 2009, 455). This theory illustrates how immigrants may be further marginalized, silenced or misrepresented because policies do not provide the means of proper communicative outlets and rights, for skilled immigrants. This theory also references gatekeepers, which in this case would refer to those responsible in the policymaking procedures and changes. Skilled immigrants are not gatekeepers so there will be minimal representation for their concerns and rights. MGT will be used to explain how these recent adjustments to the Point System do not remove the barriers to labour market entry faced by immigrants.

CDA can be described as a form of discourse analytical research that chiefly studies the way inequality, dominance and social power abuse are performed, resisted and reproduced by conversation and text present in social and political context (van Dijk, 2005). Van Dijk explains, "with such dissident research, critical discourse analysts take explicit position, and thus want to understand, expose, and ultimately resist social inequality" (2005, 352). If the Point System adjustments support Canadian employers' assessment practices, injustices and inequality may be discovered in relation to how points are awarded through certain categories. The adjustments in the Point System will be discussed in relation to the literature based on employers' practices, through the CDA lens, which should be able to reveal whether the Point System is assessing applicants with or without prejudicial circumstances. 
One of the primary critiques of CDA is that there is not an overt connection between discourse structures and the local/global social context (van Dijk, 2005). Another criticism is that "there is still a gap between more linguistically oriented studies of text and talk and the various approaches in the social. The first often ignore concepts and theories in sociology and political science on power abuse and inequality, whereas the second seldom engage in detailed discourse analysis" (van Dijk, 2005, 363).

All four perspectives are closely linked. Critical Race Theory (CRT) and Muted Group Theory (MGT) together indicate how those in power have the ability to enforce policies that promote equality imbalances for marginalized groups without being direct. This is linked to Critical Discourse Analysis (CDA), as these policies in place need to be broken down to illustrate the inequality through the language used to facilitate these policies. CRT, MGT and CDA can all be linked to Aversive Racism Theory (ART), as employers avoid hiring the more "foreign" candidate, the employers do this subconsciously because they are conditioned to believe that success in society means "sameness" and "less foreign". Since the Canadian Government has altered the Point System, their alterations are questionable. It can be argued that these changes to the Point System are filtering out skilled immigrants who do not fare well in the labour market based on their "foreignness". The Government may be enabling employers to believe their subconscious choice for sameness is acceptable, which from an MGT perspective only reproduces the silence and exclusion of those immigrants who are faced with discrimination, unemployment and underemployment. If the Government changes the Point System to accommodate immigrants who can easily assimilate, this is an indication of "institutional racism", which is then reflected and or upheld in work organizations. Employers become conditioned to 
believe that Canadian experience and credentials are superior to others, and this negatively impacts immigrants with foreign attributes, as they continue to be disregarded which can be explained through ART, and it becomes difficult for employers to change this practice when the Government changes policies to fit these hiring beliefs and practices.

The data collection for this MRP was strictly based on published materials and credible website sources such as multiple pages of Citizenship and Immigration Canada. There is currently no academic literature written after the recent changes to the Point System. However, significant reliance in this paper is placed on the CIC website and a media source, in order to access information on the recent adjustments to the Point System.

The research conducted will be analyzed utilizing both a qualitative and quantitative approach. Qualitative data analysis involves all data that is not numerical, which Archer and Berdahl define as "the non-numerical examination of reality, typically through the use of verbal depiction" $(2011,378)$. This study is primarily qualitative as it is based on a literature review and policy analysis, which highlights the changes in the immigration policy regarding the Point System. The literature will be analyzed through an eclectic combination of theoretical perspectives - CRT, MGT, ART and CDA. Qualitative observations and inferences will be made based on the evolution and development of the Point System to the present day in relation to the literature based on Canadian employers' assessment practices.

Quantitative research involves numerical values, which Archer and Berdahl define as "the numerical examination of reality, typically through the use of statistical analysis" $(2011,378)$. The statistics of interest will involve the success rates of skilled 
workers, which can be found on CIC's website. For example, under graphs that show skilled workers being able to reach and surpass the Canadian average for earnings.

The numbers can be used in the analysis through descriptive statistics such as means and standard deviations, for example to indicate the average of immigrants who are successful in the labour work, which can lead to inferences. Archer and Berdahl define inferential statistics as, "statistics used to determine if sample statistics are representative of population parameters" $(2011,373)$. Inferential statistics will be useful in comparing combinations of the three following groups: immigrants from English countries, immigrants from non-English countries and nationals, in terms of earnings and employment opportunities. The statistical analysis is vital to the research as it provides a breakdown of how many immigrants are entering under the FSWP and which countries these immigrants are coming from, and whether or not there is a success rate based on earnings and employment.

It is essential for researchers to map out the different methodological options available to them and to select the most suitable option in relation to the research question posed. As stated, there are literature gaps that make it challenging to find literature based solely on the Canadian Point System's recent changes and there was a lack of studies conducted on the research question posed in this paper. Even with this lack of information, there is enough information to successfully carry out the Critical Discourse Analysis, and to address the research question and support the main contention of this paper. A CDA is the best tool for answering the research question, as it can be used to critically assess inequality and dominance reproduced in the selected areas pertaining to this study. Finally, it is important for a researcher to avoid any biases they may possess, so it does not taint the data collecting, analysis and the overall research. 


\section{Section II: The Evolution of the Point System}

It is imperative to understand both what the Point System is and its historical development before conducting a critical analysis. Canada's immigration objectives have changed over time. Before the Point System was introduced, it is well known that the acceptance and denial of immigrants was based on ethnic backgrounds (Green and Green, 1995). The criteria for admission of immigrants from a preferred country were minimal. These preferred countries included United Kingdom, the United States and specific Commonwealth countries, which from a CRT perspective constitutes white privilege, while potential immigrants from other countries had stiffer requirements, one being the individual's skills (Green and Green, 1995). Their sponsorship rights were also more limited compared to immigrants from preferred countries (Green and Green, 1995). In the late 1950s, there was pressure to alter this limitation, for several reasons. The post war economy was expanding and the demand for labour was increasing: "during the first decade after the end of the war and a gradual economic recovery of traditional immigrant source countries in northwestern Europe had meant a gradual easing of admission restrictions during the 1950s among the non-preferred countries" (Green and Green, 1995, 1011). It was anticipated that gaps in various occupational vacancies, would be filled, however, immigrants being sponsored were unskilled immigrants from Southern Europe. The new immigrants settled in major cities where they obtained a strong political presence, making it difficult for the Government to limit sponsorship (Green and Green, 1995). The Government failed several times to limit sponsorship of unskilled immigrants, this led to the creation of a regulatory system in 1967, which included the Point System that continues to be the framework of the Canadian immigration policy (Green and Green, 1995). 
The focus of the 1978 Immigration Act put more focus on family and humanitarian immigrants, the main goals of the Act were: “(i) to facilitate the reunion in Canada of Canadian residents with close family members from abroad; (ii) to fulfill Canada's legal obligations with respect to refugees and uphold its humanitarian traditions; (iii) to foster the development of a strong and viable economy in all regions of Canada" (Green and Green, 1999, 432). This shifted the policy from economic goals making family and refugees top priority for processing (Green and Green, 1999).

The government steered away from demographic goals in the early 1990s as economic considerations became increasingly important (Green and Green, 1999). An occupations list was introduced in May of 1991, which allowed immigrants to gain top priority and points over others if theirs was one of the preferred occupations (Green and Green, 1999). In 1992, the Conservatives passed a new Immigration Act, which gave the department the power to turn away applicants once numbers had been attained for any of the three classes - the economic, family and refugee classes (Green and Green, 1999). For Green and Green, "This, potentially, was a move toward increased use of immigration for economic policy. Indeed, the government proposed to use the new Act to reduce the proportion of the inflow [of those] in the family class from 52 percent in 1992 to 43 percent by 1995" $(1999,434)$.

The economic class presently includes the Federal Skilled Workers Program (FSWP), Provincial Nominees, Canadian Experience Class, Immigrant Investors and Immigrant Entrepreneurs. The Point System specifically deals with the FSWP, which will be the main focus of the following analysis. According to the CIC website, skilled immigrants are those who have the ability to be economically established as permanent residents in Canada (2013a). It is important to note that the Point System 
has undergone many changes since its introduction in 1967, which is illustrated in

Table 1, which shows all the changes to the Point System since its introduction in 1967.

Table 1 The Evolution of the Canadian Point System (1967)

\begin{tabular}{|l|l|l|l|l|l|l|l|l|}
\hline Factor & 1967 & 1974 & 1978 & 1986 & 1993 & 1996 & 2004 & 2013 \\
\hline Education & 20 & 20 & 12 & 12 & 14 & 21 & 25 & 25 \\
\hline Experience & -- & -- & 8 & 8 & 8 & 9 & 21 & 15 \\
\hline $\begin{array}{l}\text { Specific vocational } \\
\text { preparation }\end{array}$ & 10 & 10 & 15 & 15 & 16 & -- & -- & -- \\
\hline $\begin{array}{l}\text { Occupational } \\
\text { demand }\end{array}$ & 15 & 15 & 15 & 10 & 10 & -- & -- & -- \\
\hline $\begin{array}{l}\text { Labour Market } \\
\text { balance }\end{array}$ & -- & -- & -- & -- & -- & 10 & -- & -- \\
\hline Age & 10 & 10 & 10 & 10 & 10 & 13 & 10 & 12 \\
\hline $\begin{array}{l}\text { Arranged } \\
\text { employment or } \\
\text { designated } \\
\text { occupation }\end{array}$ & 10 & 10 & 10 & 10 & 10 & 4 & 10 & 10 \\
\hline Language & 10 & 10 & 10 & 15 & 14 & 21 & 24 & 28 \\
\hline $\begin{array}{l}\text { Personality } \\
\text { suitability/ } \\
\text { Adaptability }\end{array}$ & 15 & 15 & 10 & 10 & 10 & 17 & 10 & 10 \\
\hline Levels & -- & -- & -- & 10 & 8 & -- & -- & -- \\
\hline \begin{tabular}{l} 
Relative \\
\hline
\end{tabular} & $0 / 3 / 5$ & $0 / 3 / 5$ & 5 & -- & -- & 5 & -- & -- \\
\hline Destination & 5 & 5 & 5 & -- & -- & -- & -- & -- \\
\hline Total & 100 & 100 & 100 & 100 & 100 & 100 & 100 & 100 \\
\hline Pass Mark & 50 & 50 & 50 & 70 & 67 & $*$ & 67 & 67 \\
\hline
\end{tabular}

Source: Green and Green (1999, 433), updated years 2004 and 2013 CIC (2013).

+Points awarded depend on relationship to sponsor

*The Pass Mark varies by skill group. The total points actually equals 74 . The pass marks are: professional, 52; skilled administrator, 52; technical, 47; trades, 45.

Presently the Point System uses six selection criteria. Points are allotted for education, abilities in English and/or French, work experience, age, arrangement of employment in Canada and adaptability (CIC, 2013a). According to CIC's report on the evaluation of FSWP, “applicants who meet these minimum requirements are then assessed against six selection factors. To be eligible for a permanent resident visa under the FSWP, applicants must meet the 'minimum number of points required of a skilled 
worker' or the 'pass mark' set by the Minister. The pass mark was last set on September 18, 2003 at 67 points" (CIC, 2010, 17).

It is quite clear that the economic category is the current top priority for Canadian immigration. There is a significant increase of the economic class as it represents $66.6 \%$ of the total intake of immigrants (Alboim and Cohl, 2012). This leads to the idea that human capital forms the basis of the transformation of Canada's immigration policy. The human capital theory helps to understand why the Canadian Government increased admittance of immigrants with significant educational qualifications (Li, 2003). Education is regarded as an individual's human capital. Li expands on this definition, "it [education] represents a form of investment, usually made in formative years of a person's life, brings a return that can be realized when the person joins the labour force and earns an income commensurate with the amount of schooling" $(2003,100)$. In a capitalist economy, the human capital theory perceives society as an open market where individuals are able to freely compete with each other for financial earnings and status centered on their human capital (Li, 2003, 101). The only issue is that human capital theory does not factor in discrimination and inequality that some immigrant groups may face. The issue with the most recent changes to the Point System from 2004 to 2013 is that the adjustments prevent immigrants with unequal access to the labour market from applying.

On July 1, 2012, while these adjustments were taking place, the government announced a suspension on accepting applications, under the category of FSWP (CIC, 2013a). According to Alboim and Cohl, "decisions were made to return unprocessed, pre- 2008 federal skilled worker applications, to return all applications submitted on or after July 1, 2012 for the Federal Skilled Worker Program” (2012, 5). However, applicants with a job offer and/or entering under the $\mathrm{PhD}$ stream were and are still 
eligible for assessment and possible acceptance (CIC, 2013a). On May 4, 2013, the suspension on accepting applications ended. The main adjustments to the Point System involve age, language, foreign credentials and experience. These changes will be discussed in more details in section IV.

As can be discerned from the Table 1 above, there have been a number of selection factors over the years and some factors introduced over the years have disappeared while others have reappeared. The selection factors have changed based on the economy and population needs. They have also changed to suit the agenda of the elected government of the day. For example the recent significant focus on language fluency reflects the agenda of the current Conservative Government. One can note the significant increase of points for language on the table, for example in 1993 it was 14 points and currently it is 28 points with certain conditions (which will be discussed in detail in a latter section). This table allows one to track the significant changes of the Point System. However, the main focus of this paper will be based on the changes to the Point System from the year 2004 to 2013.

\section{Section III: The Point System Failures and Successes?}

When skilled immigrants are allowed into Canada under the Point System, they have access to the labour market. However, it is not a level playing field for all of these immigrants. According to Lowe:

Despite the high education levels of immigrants to Canada, many immigrants are underemployed and unemployed, while highly skilled jobs remain vacant. In 2006, the unemployment rate of very recent university educated immigrants was four times that of the university educated Canadian born and in Ontario, the unemployment rate of all immigrants was 2.5 times higher than that of Canadian born Ontarians (11\% vs. 4.4\%) $(2010,25)$.

It is essential to understand why immigrants are having trouble accessing the labour

market, despite their educational achievements. Some immigrants face 
discrimination, which may lead to unemployment and underemployment. Discrimination can be defined as unfairly privileging one group over another group based on specific traits such as race (Gaetner and Dovidio, 2004). Unemployment is when an individual is actively seeking an occupation but cannot obtain one. Underemployment is when an individual is employed but not in an occupation that fully utilizes their full capacity. Discrimination, unemployment and underemployment are a result of some Canadian employer's assessment practices, which undervalues immigrants because of their 'foreignness'.

The objective of the Point System is to ensure that skilled workers who meet or exceed the minimum points required under the six selection factors, will be the best candidates for entry into the Canadian labour market. In the literature review, empirical evidence has demonstrated that a number of skilled immigrants do not easily transition into their intended profession. The state has an obligation to guarantee that these skilled immigrants succeed in entering the labour market, after admitting them into Canada. Unfortunately, the state has not been able to properly address issues of discrimination, unemployment and underemployment. In addition, the state is losing revenue when skilled workers are underutilized, because they are either jobless or not using their skills to their full capacity. It is in public interest to ensure that all skilled workers occupy professions that make full use of their intellectual capacity and skills.

Immigrants are economically beneficial to society at large when earning a salary commensurate with their professional capabilities. This in turn maximizes the state's revenues because higher incomes lead to higher taxes, and it prevents immigrants from potentially becoming an economic drain. The more an individual earns legally, the more they can contribute to society as a whole, through spending, 
saving and paying taxes. When highly skilled immigrants are unemployed or underemployed, there is a high risk that they will be forced into poverty, which ends up costing the state more money through the provision of social safety nets and the loss of tax revenues.

Skilled immigrants are routinely underutilized, which comes at a considerable social and economic cost. According to Reitz:

There are two estimates of the economic impact of immigrant skill underutilization. Using quite different methodologies, they both produce figures in the range of $\$ 2$ billion annually. They both define the economic impact as the reduced value of the work done by immigrants because their qualifications were not recognized in the workplace. I calculated, based on Canadian census labour-force data, that foreign-educated immigrants earned \$2.4 billion less than native-born Canadians with formally comparable skills, because they worked in occupations that were below their skill levels. I also concluded that at least two-thirds of these unutilized foreign-acquired skills worth $\$ 1.6$ billion - are in fact transferable to Canada, in the sense that these skills would have productive value if used in the Canadian context $(2003,3)$.

Reitz cites a study conducted by Watt and Bloom, who surveyed immigrants and found that their foreign acquired skills were not being used in their present occupations. They calculated the economic cost of this underutilization and it was comparable to Reitz's estimations. Reitz argues, "this economic impact is only the tip of the iceberg. Its significance is even greater when one takes into consideration the overall trend of immigrants' declining earnings and employment success, despite rising skill and education levels. Immigrants accepted under the Point System should face no struggle to gain access to their profession" $(2005,3)$. It is important to note that most immigrants who gain entry into Canada in recent years are from racial minority backgrounds, for example $56.9 \%$ of immigrants who entered between 2006 and 2011 were from Asia (including the Middle East), compared to only 13.7\% of immigrants who entered during the same time period from European countries (CIC, 2013j). Overall disadvantages in earnings and underutilization of skills are more 
significant for immigrants from social minorities compared to immigrants of European origin (Reitz, 2005, 3): the "1996 census data showed that earnings of immigrant men of non-European origin, after adjusting for differences in education and language fluency, were between 15 and 25 percent less than those of European origin" $(2005,3)$.

Graph 1 (see below) shows skilled immigrants are able to reach the Canadian average earnings and even exceed them, yet the timeframe alters for each year represented on the graph. For example, those skilled workers who reported their earnings in 1996, took two years to surpass, the Canadian average. This graph has a number of shortcomings, which makes its accuracy questionable in terms of how representative it actually is.

Graph 1 Average employment earnings (2005\$) for skilled principal applicants by landing year and tax year, 1981-2005

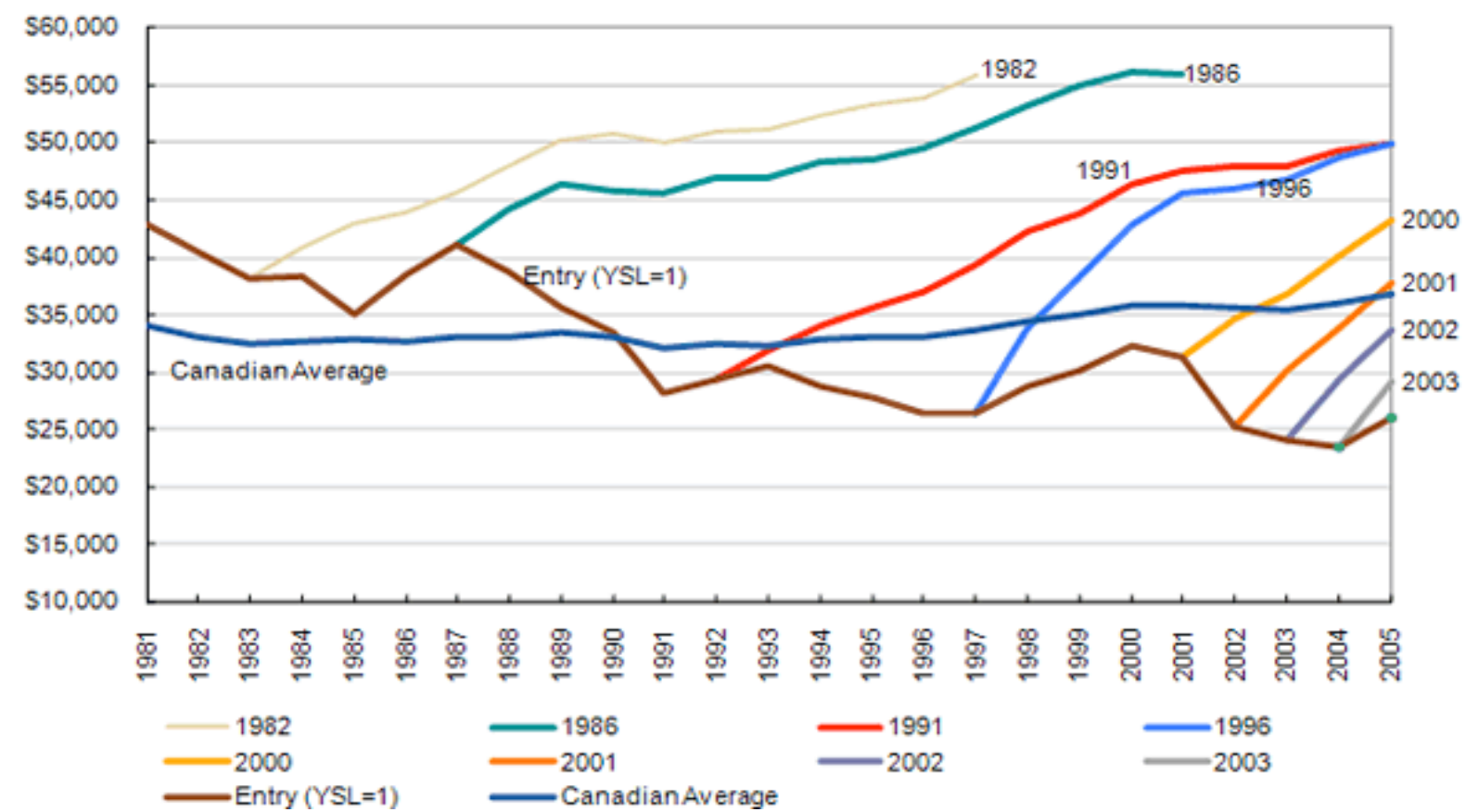

Source: Citizenship Immigration Canada (2013b).

The graph does not indicate where these immigrants are coming from, and how many of them are represented and what their occupations are. It does not include all the 
skilled immigrants who migrate to Canada because some are unemployed or underemployed, while others stop seeking employment. There is a possibility that this graph represents those with the greatest salaries. It is difficult to assume this graph is representative of all skilled workers' success in exceeding the Canadian average earnings, since the graph is only representative of those skilled immigrants who reported their earnings (CIC, 2013b). It is also not clear if skilled immigrants changed employment each year they report their earnings, for example it may take time before the skilled immigrant works in their trained field, and may have been reporting earnings based on employment they were not trained for, possibly being underemployed.

Looking at this graph, it appears that skilled workers are successful in their first year of arrival, which is not the case as presented in Grenier and Xue's study. They demonstrated that skilled immigrants were not accessing their intended occupation in their first year of arrival, and were having a tumultuous time for the first five years. After five years skilled immigrants may be able to get rid of their accents, become more fluent in English and/ or French, gain a Canadian education, which all result in greater opportunities to earn the Canadian experience they were lacking in the first year of arrival. This highlights the need to assimilate into Canadian society by becoming less "foreign" and more "Canadian" in order to succeed in the labour market. Skilled immigrant workers will not necessarily be successful in the labour market just because they were granted the right to immigrate under the FSWP and as mentioned they may be reporting earnings for an occupation they had to settle for, which may be the case in this graph.

Another discrepancy in the graph is that the average reported earnings for Canadians represents a larger portion of the population compared to skilled 
immigrants. As a result, the range of salaries for Canadians would be much larger than the range for skilled workers, possibly making the average for reported earnings by Canadians lower altogether. This average may include the earnings of Canadians who are not skilled workers, which could reflect lower wages than a skilled worker. Another interesting observation based on the graph is that as the years of immigration entry increases, the average earnings for skilled immigrants gets lower. For example from 1982 to 2003, one can see the skilled immigrants earnings were well above the Canadian average earnings compared to those skilled immigrants in 2003. This could be because the immigrants accepted in 2003 compared to those who arrived in 1982, may have been from more non-English and non-French countries.

Even though this graph shows the average earnings of skilled immigrants surpassing the Canadian average earnings, the Pendakur and Pendakur's (2011) study demonstrates earning gaps for Canadian visible minorities. There is every likelihood that the composition of the average earnings of skilled immigrants could be broken down to indicate a difference of earnings between skilled workers, where minorities would be on the lower end of earnings compared to "white" skilled workers. From a CRT perspective, these earning differentials constitute white privilege which further marginalizes minorities and from a MGT perspective it would point to unwillingness of those in power to eradicate these earning differentials as they are not affected by the injustice of pay differentials based on race. There is a chance if this graph was reconstructed to show the ethnicity of the workers that there may be interesting findings related to ethnicity and earning power. However, only an average is shown, which does not indicate any discrimination through earnings on this graph.

Reitz's findings are useful in understanding the economic losses and harmful effects on Canadian society as a result of the underutilization of skilled workers: "in 
1996, 59 percent of native-born men with bachelor's degrees were working in knowledge occupations, compared with only 35 percent of recent immigrants (arriving in the previous 5 years) with bachelors' degrees. The corresponding figures for women were 57 and 28 percent" (Reitz, 2005, 6). Immigrants struggle economically even after being in the country for five years. It is important to note that these statistics are not up-to-date. One can infer that these statistics would represent a greater failure in today's labour market for skilled immigrants from non-English backgrounds. This inference may be true, when considering all the studies already mentioned in this paper and by comments made by the current 2013 Minister of Citizenship, Immigration and Multiculturalism for Canada, Minister Jason Kenney, which will be explored in the following section.

\section{Section IV: The Recent Adjustments to the Point System, Reflecting Discriminatory Practices?}

It is clear that the Point System was created to select highly skilled immigrants to fill occupational vacancies that will add value to the Canadian economy. The framework of a Critical Discourse Analysis (CDA) will be used to assess the recent Point System adjustments and the events related to these changes. A CDA will point to the inequality and injustices linked to the reforms of the FSWP. In addition, an analysis of a political speech made by Minister Jason Kenny will be deconstructed, to help identify the reasoning and the discourse behind the changes to the Point System. Finally, the theoretical perspectives of CRT, ART and MGT will be used to explore the impacts these changes have on society, law and discrimination. This section will be divided into the following eight subsections: (a) Deconstructing Minister Jason Kenney's Speech, (b) The Adjustments to the Point System, (c) Language, (d) 
Experience, (e) Education, (f) Age, (g) Adaptability and Arranged Employment and finally (h) Other Discrimination Concerns.

\section{(a) Deconstructing Minister Jason Kenney's Speech}

The first part of this section deals with the Minister Jason Kenney's speech prior to the May 4, 2013 adjustments to the Point System and the changes brought through the exercise of ministerial power, which effectively allowed for the changes to be uncontested. In a December 19, 2012 speech, Minister Jason Kenney said:

The government's number one priority remains jobs, economic growth, and long-term prosperity. The new Federal Skilled Worker Program criteria will ensure Canada is selecting the skilled immigrants our economy needs, who are the most likely to succeed and fully realize their potential in Canada. For too long, too many immigrants to Canada have experienced underemployment and unemployment, and this has been detrimental to these newcomers and to the Canadian economy. Our transformational changes to the FSWP will help ensure that skilled newcomers are able to contribute their skills fully to the economy as soon as possible. This is good for newcomers, good for the economy, and good for all Canadians (2013c).

The news release quoting his speech outlined the main changes to the FSWP that are supposed to improve Canada's immigration system. In conducting a CDA of Minister Kenney's remarks there are a number of striking elements that come to the surface. It can be true that "the government's number one priority remains [to be] jobs, economic growth and long-term prosperity" but this is hardly convincing for the following reasons. As discussed in literature review there are many immigrants particularly those from non-English and non-French speaking countries, who do not succeed in finding jobs in their intended profession, especially in their first year of arrival. Some of these immigrants who arrive under the FSWP do not end up in their intended profession. If jobs are a number one priority, then why are there not more programs and assistance available to those who are facing obstacles in penetrating the labour market? Integrating immigrants into the labour market will logically lead to 
economic growth and long-term prosperity. In addition, it will help immigrants to avoid becoming an "economic drain" by keeping them away from unemployment.

As argued in Section III, there would be more economic growth if the underutilization of immigrants' skills were avoided. The state that implements an immigration Point System should be obligated to support applicants in their efforts to integrate the labour market when this is a nationwide problem. If the government was to offer such measures, the immigrant will be held accountable for fully accessing any programs of assistance. As for "long-term prosperity", this is highly doubtful considering the new emphasis on the independence of economic immigrants and the temporary status of the foreign worker program, economic immigrants are not arriving with a family unit most times, they are coming as individuals possibly leaving behind a family, which can deter long-term commitment to Canada.

Minister Kenney's next statement, “The new FSWP criteria will help ensure Canada is selecting the skilled immigrants our economy needs, who are the most likely to succeed and fully realize their potential in Canada", could be suggesting that the skilled workers Canada selected prior to the changes have not been successful and are not contributing to economic growth and development. Left unexplained is why labour market integration was an issue and as the research cited thus far suggests, much of it has to do with various forms of discrimination. Immigrants should "fully realize their potential" in addition it is the employers who should also be realizing the immigrants' full potential. A lot of these skilled immigrants have been educated and have a great deal of experience in their fields prior to their arrival in Canada so the potential is there despite their failure to successfully enter the labour market. CIC might consider spending time and effort educating employers. 
Minister Kenney discusses unemployment and underemployment in the labour market, these issues should be directly solved rather than changing the FSWP to filter out immigrants who could potentially face discrimination. Minister Kenney correctly states that unemployment and underemployment are detrimental to newcomers and to the Canadian economy. However, adjusting the Point System will not solve these two issues because the Point System is no longer directly associated with the immigrants experiencing unemployment and underemployment. The Point System can prevent certain immigrants who have less chance of assimilating from entering but this will not solve the problem for those currently facing these challenges.

Minister Kenney states that the changes to the FSWP "will help ensure that skilled newcomers are able to contribute their skills fully to the economy as soon as possible." Yet the skills and capabilities of the highly skilled immigrants who are presently in Canada and who are unemployed or underemployed are not contributing to the economy. Barriers to their full participation need to be eradicated. The fact that the state is not dealing with these barriers reflects institutional racism, as it is the collective failure of the Government and employers to provide the professional service to ensure minority groups are being treated equally in the labour market. Employers will not unilaterally change their practices, as from an ART perspective, their practices can be seen as cognitively privileging "whiteness" in the labour market, and which underlies a further silencing of minority groups precisely because services are not in place to represent their rights and perspectives.

Finally, Minister Kenney says, "This is good for newcomers, good for the economy, and good for all Canadians". It can be argued that the changes to the Point System do not benefit all Canadians equally, because the population includes all of those who, despite being accepted into Canada, face discrimination in their job search 
or see their credentials and work experience being disregarded. The adjustment to the Point System may add even more burdens on those who already experience challenges during their job search. Therefore, the recent adjustments to the Point System do not directly address the current problems and obstacles that some skilled immigrants are still facing. In addition, the recent changes to the Point System seem to favour the current selection process of some Canadian employers. Yet, Alboim and Cohl argue "There is danger, however, in devolving too much responsibility for selection to employers. This is because employers seek people who can contribute immediately at the least cost" $(2012,19)$. The government is looking for immigrants to help with the short-term labour needs, and not is thinking about the future of Canada. It seems that its main interest lies with economic immigrants.

These changes to the immigration policy as Alboim and Cohl point out, are based on insufficient information:

The challenge of making evidence-based policy decisions is exacerbated by two decisions that reduced the research, data collection, and analysis available to government for policy analysis. The first change was the elimination in 2011 of the mandatory long-form census, which provided statistics for longitudinal research to assess how immigrants were faring in Canada. The second change was the 2012 decision to defund the Canadian Metropolis and affiliated Centres of Excellence across the country which enabled academics and non-governmental bodies to conduct and share a broad range of immigration-related research $(2012,65)$.

Therefore, these changes that Minister Kenney has imposed to the FSWP are based on limited research.

In addition, Alboim and Cohl suggest, “... these requirements could have unintended consequences. For example, source countries will change so that applicants from English or French speaking countries will predominate. This will have an impact on traditional source countries such as China" $(2012,23)$. The second generation of Chinese immigrants has proved to be successful in Canada which means 
that restricting immigrants from countries like China will be a terrible loss to Canada (Alboim and Cohl, 2012, 23).

It is important to understand several elements before exploring each change to the Point System. Alboim and Cohl's report also outlines very interesting details that lead to the Point System adjustments along with the other changes in the Immigration Policy. They argue that changes to the Immigration Policy used to be only attained through legislation and regulations (Alboim and Cohl, 2012, 11): "legislation would typically be preceded by public consultation, task forces, discussion papers, committee hearings, and parliamentary debate. Regulations were also the subject of consultation before being approved by the federal Cabinet"(2012, 9). However, after the 2008 Budget Implementation Act was introduced in February of the same year, this budget bill changed the Immigration Refugee Protection Act (IRPA) of 2002 (Alboim and Cohl, 2012). Alboim and Cohl explain, "as a result, the Minister became authorized to issue Ministerial Instructions to immigration officers"(2012, 9). These changes can be viewed as unilateral and undemocratic. Alboim and Cohl highlight the fact that the Minister can make decisions without having to go through parliamentary processes and without public consultation (2012). An example of the exercise of this power is the decision to return unprocessed applications to the FSWP received pre2008, because of the new adjustments being established for the Point System. This rash action can have a considerably negative impact on future applicants to FSWP, as "they may not wish to invest their time, energy, money, and dreams on a country that changes the rules continuously and does not even commit to assessing all applications" (Alboim and Cohl, 2012, 11). The return of applications seemed unfair and very "un-Canadian". 
In the Toronto Star, Black reports on the then proposed changes and the application returns: "The government rejects certain occupations, requires certain language skills, and makes immigration officers available in only certain parts of the world. Without notice, in 2012, it also arbitrarily rejected a backlog of nearly 100,000 applications, representing 280,000 people, many of whom had waited years to come to Canada" (Black, 2013). This highlights discrimination, as immigration officers were strategically located in certain countries. Minister Kenney introduced the adjustments to the Point System on May 4, 2013, that appear to have the same discriminatory impact on immigrants as past policies. Each adjustment to the Point System will be described in the following subsections.

\section{(b) The Adjustments to the Point System}

Table 2 below, shows the most recent changes to the Point System. Note the "proposed system maximum points" are now officially the point breakdown. The new changes will be explained and critiqued in the following subsections.

Table 2 Point Changes

\begin{tabular}{|l|l|l|}
\hline $\begin{array}{l}\text { Selection based on } \\
\text { objective factors }\end{array}$ & $\begin{array}{l}\text { Current System Maximum } \\
\text { points: }\end{array}$ & $\begin{array}{l}\text { Proposed System } \\
\text { Maximum Points: }\end{array}$ \\
\hline Education & 25 & 25 \\
\hline Language & 24 & 28 \\
\hline Work Experience & 21 & 15 \\
\hline Age & 10 & 12 \\
\hline Arranged Employment & 10 & 10 \\
\hline Adaptability & 10 & 10 \\
\hline Total: & 100 & 100 \\
\hline
\end{tabular}

Source: (CIC, 2013d)

\section{(c) Education}

The education selection factor has an additional requirement that suggests education attained in certain countries is more valuable over others. The point 
maximum remains the same though there are two changes. The first change disregards the number of years associated with education, CIC states,

Education points [were] awarded based on the credential (such as a postsecondary diploma) and the number of associated years of education. The years of education requirements is intended to help ensure the quality of the credential. However, the years of education required reflect Canadian educational systems and do not take into account country-to-country variants in school system (CIC, 2013h).

The change seems sufficient and adds to the FSWP's point distribution because it is important to take into consideration the "country-to-country variants". The only issue is that the other selection criteria lack this consideration, which makes the Point System adjustments seem inconsistent.

The second change involves the requirement for each applicant to have their education assessed at one of four approved assessment centers and to include their Educational Credential Assessment (ECA) report with their application (CIC, 2013h). This is a direct response to the practice of some Canadian employers discounting immigrants' education attained prior to their arrival in Canada. This places more responsibility on the applicant to have this assessment completed, (at their own cost) prior to applying for immigration. If the applicant does not receive approval from the assessment center for educational credentials, the applicant will not be eligible to apply under the FSWP. The idea seems fair, as it saves the applicant time and money in applying if their educational credentials will not be accepted because they are not "comparable" to Canadian standards. However, using a CRT lens it can be argued that this suggests that Canadian education and standards are superior to other countries whose education is not recognized as being valuable enough to apply under FSWP. This sends a negative message to other countries. Another issue involves all the immigrants here who were previously accepted under the FSWP: should they all spend their time and money re-educating themselves, as 
they face being unemployed or underemployed? This is a reality as the studies discussed in literature review have highlighted.

Mirchandi's (2004) study provides the case study of the Rijhwanis who had to reeducate their selves in order to assimilate to society and sound less foreign. In the Alboim et al. (2005), their study finds that Canadian employers are not familiar with foreign obtained education, so they do not feel obligated to hire that applicant. This ignorance is directly reflective of the employers as gatekeepers who only utilize their local knowledge when assessing applicants. This effectively excludes applicants with unfamiliar foreign education. Lowe (2010) addresses the idea that highly skilled immigrants enter Canada with high levels of education and statistically they have a 2.5 times higher unemployment rate than those who are educated in Canada. One must consider even if the applicant passes the 67-point minimum, there is no guarantee that Canadian employers will recognize the foreign education and value it as much as Canadian education. Again, the responsibility is on the Government to address this issue of foreign education when it comes to employment in the labour market.

\section{(d) Language}

The language selection factor has been adjusted to limit applicants from nonEnglish or non- French speaking countries. The most significant change to the language selection factor is that there is now a language fluency test required. This language test must be completed at the applicant's own cost, before the application is submitted. The applicant is tested in four areas, which include speaking, listening, reading and writing, for the first and second official languages (CIC, 2013e). CIC also indicates that the tests must be completed with one of the approved language test centers. As Table 2 indicates prior to the 2013 changes, the language factor maximum 
total was 24 points and presently it is 28 points. Not only is there an increase in points for language, the breakdown for both official languages has changed. Instead of a maximum total of 16 points for the first official language and 8 points for the second official language, it is now respectively 24 points and 4 points (CIC, 2013e). This adjustment has an element of inequality for a number of reasons.

First the concepts that appear on the test may not be familiar concepts in the applicant's geographic region. Second, the majority of applicants who are strongly fluent will be from English or French speaking countries. Third, someone may be fluent in both languages but not be strong in both languages and as a result they will now receive less points for knowledge in the second official language. Fourth, some occupations do not require strong fluency in language and these applicants could be very talented in a particular field, yet they may not be fluent enough in either of the official languages. Fifth, the language fluency test may be faulty in that it does not test terms relevant to the applicant's field of specialization. An applicant may well be fluent in English or French terms that pertain to their field of specialization and not fully comprehend the terminology on the language fluency test. It could also work the other way where the applicant is familiar with the terminology presented on the test but not fluent when it comes to maybe more intricate terms relevant to their field. Passing a fluency test does not guarantee that the applicant has the niche language of their profession. It is possible the same problem of the applicant not being able to penetrate their profession is reproduced and this nullifies the point of the language fluency test. With respect to the language factor changes, CIC states,

A 2005 Statistics Canada study found that employment rates of immigrants increased with their ability to speak an official language. It also found that language proficiency had the biggest impact on the immigrant's ability to work in either a high-skilled profession or their intended field (CIC, 2013f). 
If the statistics are accurate, then CIC should take responsibility for the immigrants who were previously accepted under the Point System prior to the changes. The state should be responsible for the citizens who were accepted and who have struggled because of language proficiency problems. If language is the issue then it should be dealt with in a proper manner and not neglected. If immigrants are costing the state by being underemployed or unemployed, the state should solve this problem with language classes. Of course, the immigrant would have a responsibility to make use of these services if they were offered to help with succeeding in their intended profession. This will be covered in the policy recommendations section.

Another issue with the language component is the fluency test does not deal with "undesirable" accents. As mentioned in the literature review, some accents can hinder an immigrant's chance to accessing an intended occupation, even if the immigrant passes the fluency test. This change does not reflect support for the obstacles some immigrants experience in having an accent, as Sadiq (2005) indicated the accent is representative of ethnic difference. Munro (2003) noted the same idea; in his study employers were less likely to accept certain accents. If accents are a problem then how will language fluency testing fix this? Will language fluency testing filter out undesirable accents? The language fluency test already reinforces some Canadian employers' discriminatory attitudes when it comes to language, ensuring that the candidates pass the test before application. From an MGT perspective, such attitudes are a means to silence the marginalized because they do not provide a voice for those who do not sound Canadian enough or who do not have a desirable accent. The state by enacting such a policy de-facto reproduces the subconscious attitudes, which employers use to select immigrants who are more fluent in speech and who are “accentless". 
Pendakur and Pendakur (2002) found an association between minority language and under-earning. Such employer practices require state intervention and need to be dealt with by the state and the Human Rights Commissions in order to be rectified. However, this issue is not being dealt with, as the Government looks to ensure that immigrants speak the language of preference. There is clearly a problem with the way some Canadian employers' dismiss an immigrants' ability because of an "undesirable" accent, which can be identified as systematic racism, should the state not inform and educate employers about the implications of this practice? It is clear that these adjustments to the language factor lean in the favour of applicants from English and French speaking countries. The language factor alone speaks volumes about the direction the Canadian Immigration Policy has taken.

Utilizing the Critical Race Theory (CRT) lens, it is clear the changes to the language factor privileges immigrants from English and French speaking countries over those from other countries. Through the new changes to the Point System, the Government has made significant changes to the Immigration Policy that potentially violate the Canadian Charter of Rights and Freedoms by marginalizing minorities and favouring those from English and French speaking countries, which will be discussed in Section V. This is a form of institutional racism.

These adjustments appear to support the Canadian employers' assessment and employment practices, as the Point System now manages to filter out applicants based on language proficiency, that employers would necessarily hire.

\section{(e) Experience}

The adjustment to the total maximum points for the experience selection factor illustrates the lack of appreciation for some foreign obtained experience. Prior to the 2013 changes the maximum total was 21 and presently it has decreased to 15 . 
Experience should be regarded as very valuable when it comes to work, but under the new system, fewer points are awarded for relevant experience. Another change to the experience selection factor is that it has been broken into ranges as shown in Table 3:

Table 3 Point Changes for Experience Factor

\begin{tabular}{|l|l|}
\hline Experience & Maximum 15 Points \\
\hline 1 year & 9 \\
\hline $2-3$ years & 11 \\
\hline $4-5$ years & 13 \\
\hline 6 or more years & 15 \\
\hline
\end{tabular}

Source: (CIC, 2013g)

The experience selection factor is only relevant when the applicant has an occupation that appears on the National Occupational Classification (NOC) list. CIC describes the NOC as, "a system used to classify jobs in the Canadian economy. It describes duties, skills, talents and work settings for different jobs. CIC uses the 2011 edition of the NOC to assess skilled worker applications" (CIC, 2013g) In addition, the list will provide a description of the tasks for each occupation and there must be a match with one's previous experience to the list of tasks in order to qualify for points (CIC, 2013g). Alboim and Cohl draw attention to the interesting fact that provincial representatives were opposed to the NOC list:

An evaluation of the first set of Ministerial Instructions revealed that provincial representatives interviewed during the planning phase had been opposed to the concept of a national occupation list for the Federal Skilled Worker Program and reacted negatively to the list that was established, claiming it did not respond to their needs. Nonetheless, Citizenship and Immigration Canada went ahead with the Ministerial Instructions to introduce the occupation list $(2012,17)$.

This was another unilateral federal decision. CIC explain the reasoning for this significant change to the experience selections factor as necessary: 
The Federal Skilled Worker program places more weight on work experience than other countries. The overall value of work experience points in the selection grid represents too large a share. Currently, with as little as four years of foreign work experience, an applicant has already earned 21 of the points required to meet the pass mark of 67 (CIC 2013g).

Through a CDA lens, it can be argued that the reason why Canada's previous FSWP placed great weight on work experience from foreign countries compared to other countries is because Canada has an obligation to uphold the relevant components of the Constitution, which will be discussed in more detail in Section V. Canadian experience should not be viewed as superior to experience obtained elsewhere because experience in a field is relevant. CIC also does not find that 4 years of foreign work experience merits 21 points with no proper explanation and instead argues “... foreign experience is a weak predictor of success in the Canadian labour market" (CIC, 2013g). This argument is tautological as foreign experience is considered a weak predictor of success only because Canadian employers do not accept it. It is not accepted by Canadian employers, who tend to prefer national or globally recognized education, as discussed in the literature review. Again the point distribution adjustment supports the discriminatory assessment practices of Canadian employers by decreasing the maximum points for work experience and placing a range to accompany the amount of points based on years.

CRT helps with understanding that there is less acceptance of experience from foreign countries, which disadvantages applicants without Canadian experience. Canada has an obligation to the immigrants who arrived here under the FSWP to ensure that their foreign experience is accepted. Again, adjusting the point distribution for work experience does not solve this issue. Even with the work experience maximum being decreased, if an applicant passes the point system minimum of 67 , it is not clear how this ensures that employers will accept the applicants' foreign 
experience? It does not ensure anything, which is why the Canadian state has an obligation to educate employers on the significance of foreign experience because it is the state that accepts the applicant based on their previous experience. It can be inferred that with changes in the other three categories combined, the type of foreign experience of applicants who pass the language fluency test and have recognized foreign education will in fact be the so called "desired" foreign work experience. The Point System has been crafted in a way to filter out the "undesirable" immigrant, the minority immigrant.

The lack of recognition of foreign experience highlights aversive racism towards non-Canadian experience. It is significant to consider that foreign experience may possibly be more significant than experience acquired in Canada. The nonCanadian experience could have been acquired at a reputable work organization or educational institution that is not familiar to Canadian employers or the experience could have been acquired over a lengthy time period. For example a doctor practicing medicine in a foreign country for 20 years is clearly more experienced than a doctor practicing for 1 year in Canada. This is why the lack of recognition of foreign experience is a discriminatory practice and unfair. The various studies in the literature review indicated experience that was not Canadian was undervalued. Shinnaoui and Narchal's study indicated that those with experience from culturally and linguistically diverse backgrounds fare worse than those immigrants from the local and English speaking background applicants. This practice is reflected through what ART would identify as white privilege (Gaertner \& Dovidio, 1986) and at the same time this practice disregards those with experience further marginalizing the minority, as their experience holds no value and is regarded as inferior. The Government reinforces this by making foreign experience worth less points, this is an example of where applying 
a CRT lens leads to an understanding of institutional racism, where law and power come together to disregard foreign obtained experience. This point change by the Government only strengthens employers' disregard for foreign experience. Grenier and Xue's study showed how accumulation of Canadian experience over time for immigrants, allows for penetration into the labour market. This should not be the case when these immigrants were previously accepted for their skills and experience. However, the state is reinforcing this disregard by changing the points allotted for foreign experience.

\section{(f) Age}

The age selection factor has also been adjusted to reward younger applicants with more points depending on their age. The age adjustment does not illustrate cultural discrimination but rather age discrimination, which will be discussed briefly. The maximum was 10 and has been increased to 12 points. The point distribution prior to the point adjustment was 10 points for 21 to 49 , then minus 2 points each year after 21 or 49, making 17 and 53 the last two ages to receive 2 points (CIC, 2013i). Presently, 12 points are awarded for 18 to 35 years of age, minus 1 point each year till 46 years of age, this shows a significant difference in the ages FSWP is willing to accept (CIC, 2013i). CIC explain the changes:

Research has shown that age at immigration is a significant factor in immigrant outcomes. Immigrants who arrive between the age of 20 and 30 have been found to have the greatest economic impact on the receiving country. Younger immigrants have higher rates of employment and earnings than older immigrants. By contrast, immigrants aged 45 years and older experience unemployment rates almost double those aged 25-34 years. Younger immigrants are more likely to acquire Canadian work and study experience, adapt more quickly to their new environments and make a greater contribution to the economy. (CIC, 2013i)

CIC refers to research and does not indicate where the research comes from.

The Point System can favour younger applicants for a number of reasons, one being 
the "younger immigrants are more likely to acquire Canadian work and study experience", which again places emphasis on the value of Canadian experience over other experience from other countries. Another reason is that the younger the immigrant is, the more it will be that a family unit will not accompany them. Finally, younger immigrants would less likely utilize the health services compared to older immigrants. Again, the increase in points for age indicates that there is less emphasis on other categories - for example less points for experience is simultaneously linked to younger age and more experience tends to be linked with someone of older age.

\section{(g) Adaptability and Arranged Employment}

The two selection factors of adaptability and arranged employment have changed the least with the point total maximum remaining at 10 each for the total maximum. Adaptability focuses on how well the immigrant will be able to adjust to the Canadian environment. Applicants can receive additional points for previous work or study in Canada. They can also receive additional points for having relatives in Canada and if their spouse is educated and fluent in either or both

official languages as determined by the new language fluency test (CIC, 2013f). Again, applying a CRT lens it can be argued that minorities may not be reflected well in this category, because of the lack of experience in Canada through work or study. In addition their spouse may not pass the fluency test while an immigrant with a spouse from an English or French-speaking country would most likely pass the test thereby privileging the more desirable group of immigrants.

Arranged employment remains the same except visa officers will be more stringent in making sure the employer is legitimate to avoid the possibility of 
fraudulent job offers, which is a good safety precaution to take, as it equalizes for others who do not have arranged employment opportunities.

(h) Other areas of Discrimination

The recent changes to the Point System directly reflect areas of discrimination that were presented in the studies highlighted in the literature review. These changes may yield a lower number of applicants with foreign sounding names, but this is unlikely. In Oreopoulos' study individuals involved in candidate selection and the hiring processes were biased on the basis of non-Western sounding names, without even being aware of it. The changes to the Point System cannot address the issue of name discrimination, which seems to be a significant problem. The Government needs to address this issue, through properly educating Canadian employers to avoid name discrimination, perhaps through a comprehensive antiracism program.

Even though highly skilled immigrants are granted permanent residency in Canada, this does not ensure that they will experience equal opportunity in the Canadian labour market. The studies referred to above and the empirical evidence presented in the studies suggests that those highly skilled immigrants succeeding in the Canadian labour market are most likely from English speaking countries.

It is clear after investigating the recent adjustments to the Point System there is a degree of what CRT refers to as "Institutional Racism" (Gilborn, 2006). The Federal Government is the institution of predominant power that has realigned its policy by systemically bringing discriminatory elements into the selection process of immigrants applying under the FSWP. The Federal Government has advertently or inadvertently adjusted its Point System to reproduce the stereotypical and 
discriminatory assessment practices of some Canadian employers. Finally, these adjustments go against the Canadian Constitution, which will be explored in the following Section.

\section{Section V: The Adjustments to the Point System Undermines Canada's}

\section{Constitution}

After conducting a thorough analysis of the recent adjustments to the Point System, one can see that the FSWP attempts to restructure the preferred group of immigrants. This, it will be argued, violates The Canadian Charter of Rights and Freedoms and the Multiculturalism Act. The theoretical framework of Muted Group Theory (MGT) will be used to understand the impact of these changes on minority groups, who are further marginalized and denied entry into Canada based on their cultural and ethnic differences.

Canada is the first country to adopt the Multiculturalism Act of 1985. The analysis in Section III clearly indicates that the Federal Government has a responsibility to ensure that all citizens have equality of opportunity regardless of their cultural differences and have equal opportunity in and access to the labour market. Both Canadian employers and the Federal Government appear to violate the central tenets of the Multiculturalism Act. A country is sovereign and has the right to set its own policies; however, when these policies violate the central foundations of the country's constitution, this is highly problematic. The Canadian Government has an obligation to follow both the Charter of Rights and Freedoms and the Multiculturalism Act when it comes to policy making.

There are many tenets of the Multiculturalism Act that have been violated by the changes to the Point System. Section $5(1)(d)$, of the Act obligates the state to:

Encourage and assist the business community, labour organizations, voluntary and other private organizations, as well as public institutions, in 
ensuring full participation in Canadian society, including the social and economic aspects, of individuals of all origins and their communities, and in promoting respect and appreciation for the multicultural reality of Canada (CMA, 1985).

This means that the Minister has an obligation to ensure that the institutions listed, including labour organizations, are responsible for allowing citizens to participate equally despite ethno-racial differences. The current problems in the labour market are not being addressed with respect to this basic tenet. Instead the FSWP is being altered to ensure that those with cultural differences are not being accepted into the country.

Section 5(1)(g) of the Act states the Minister has an obligation to, "Assist ethno-cultural minority communities to conduct activities with a view to overcoming any discriminatory barrier and, in particular, discrimination based on race or national or ethnic origin" (CMA, 1985). It is evident the state is not providing proper assistance to immigrants who face unemployment, underemployment or underutilization because nothing is done to prevent employers from assessing immigrants on superficial criteria such as foreign names, accents, experience and education. The Federal Government has not addressed these issues; instead it has allowed the adjustments to the Point System to be carried out. The Federal Government is in effect reproducing the discriminatory practices of employers by filtering out "undesirable" immigrants. Bias and discriminatory attitudes end up being reinforced and legitimized by allowing and justifying this type of changes to the Point System.

Section 3(2)(a), of the Act states the Minister must, "ensure that Canadians of all origins have an equal opportunity to obtain employment and advancement in those institutions" (CMA, 1985). The empirical evidence presented in this paper suggests that equal opportunity in employment for many immigrants is a myth. 
According to the equality provisions of the Canadian Charter of Rights and Freedoms S, 15. (1) "Every individual is equal before and under the law and has the right to equal protection and equal benefit of the law without discrimination based on race, national or ethnic origin, colour, religion, sex, age or mental or physical disability" (CCHRF, 2013). Formal equality should lead to substantive equality where everyone has equality of opportunity. The data presented thus far suggests that many immigrants face discrimination in the labour market and now with the changes to the Point System, this is increasingly true for those seeking to migrate to Canada.

If the Federal Government of Canada changes policies, they should be consistent with the equality provisions of the Charter. Potentially violating both the Charter and the Multiculturalism Act speaks volumes about what kind of society the current Federal Government seeks to build - one where immigrants who assimilate into Canadian society are privileged.

Utilizing Muted Group Theory (MGT) it is clear that the skilled immigrants being discriminated against are now being further marginalized because the state does not protect their fundamental rights under the Constitution. The Government is fundamentally restructuring the Immigration Policy in a manner that adds further to this marginalization of minority groups. As mentioned earlier both employers and the Government that engage in this discrimination, are gatekeepers who either write the policies or discriminate against immigrants who have accents, whose skills, prior experience and education are significantly undervalued. The latter are not being given the chance to succeed, which results in their further marginalization.

\section{Section VI: Policy Recommendations}

There are a number of policy recommendations to be made after conducting the Critical Discourse Analysis. 
1. The state that implements an immigration Point System should be obligated to support applicants in their efforts to integrate into the labour market. There should be more programs and assistance available to those who are facing obstacles in penetrating the labour market. These programs can help with resume development, networking and self-marketing in order to help the applicant avoid a long transition for entering the labour market.

2. The Canadian government should take responsibility for immigrants who previously entered Canada via the FSWP. These immigrants should be employed to their full capacity and the Government should support this by reaching out to them and providing services such as language classes based on profession specific language. This might be costly in the short run, but in the long term it will be beneficial to the Canadian economy once these immigrants are used to their full capacity. There is also an onus on the immigrant to take advantage of these language classes in order for this to work. However, it is important to note that this recommendation, does not suggest that immigrants should be punished for having an accent or speaking multiple languages. These classes are in place to help immigrants learn the terminology that will aid to greater success in their profession, as language is a key component of communication.

3. The Government should readjust the Point System in order to give equal opportunity to immigrants from all backgrounds - particularly since the Charter of Rights and Freedoms has strong equality provisions and redress of discrimination provisions.

4. CIC might consider spending time and effort educating employers. The Canadian state has an obligation to educate employers on the significance of foreign experience 
5. The Government should implement a policy that advocates more tolerance and respect for ethnic and cultural differences in the Canadian labour market. Employers who discriminate on any number of the enumerated ground should be brought before human rights tribunals. There should be greater enforcement of non-discrimination legislation at both the federal and provincial levels.

6. State sovereignty is a given, however the Canadian state should not violate its own Constitution and the legislation it has in place to protect ethno-racial minorities. The Government of Canada should undertake a risk analysis with respect to the changes it has implement to the Point System. Such a risk assessment could look at the potential Charter violations, the impact on Canadian society, and the impact on potential immigrants.

\section{Conclusion}

Immigration is necessary for the socio-economic development of Canada. Immigration policy should reflect the core tenets of the Charter of Rights and Freedoms. What appears to be the case however, is that recent changes to the Point System are an attempt to restructure the "type" of immigrant likely to apply to come to Canada. It has been argued that this constitutes systemic institutional ethno-racial discrimination. After analyzing the various studies through the theories of aversive racism, critical racism and muted group, the common themes that emerge are that immigrants endure unemployment, underemployment, and are underutilized. In addition, employers discriminate against them on a number of grounds including their accent, place of education, and lack of Canadian experience. Employers prefer applicants who are fluent in English or French, accent free, and non- foreign with respect to their name, experience, education and credentials. 
The Federal Government has to do more to ensure a smooth and equitable transition into Canadian society for immigrants who are non- white and non- English or non- French speaking as they struggle the most. The government has altered the Point System to filter out immigrants deemed to be problematic, by awarding more points for language fluency after testing and less for foreign experience. The new Point System ensures that immigrants have their foreign credentials assessed beforehand and awards more points for younger immigrants while underemphasizing experience. Utilizing a critical discourse analysis, it can be argued the state is advertently or inadvertently allowing some Canadian employers to dictate what kind of immigrants should be accepted under the Point System. This is in clear violation of the Multicultural Act and The Canadian Charter of Rights and Freedoms.

The state has an obligation to ensure that immigrants, who are struggling in the labour market after being accepted via the FSWP, have equality of opportunity - a right consistent with the Charter of Rights and Freedoms. Unfortunately the Canadian state is not living up to its obligations under both the Charter and the Multiculturalism Act and the recent changes to the Point System only reinforces this perception. 


\section{References}

Alboim, N. \& Cohl, K. (2012). Shaping the future: Canada's rapidly changing immigration policies. Retrieved on May 1, 2013 from the URL: http://maytree.com/spotlight/shaping-the-future-canadas-rapidly-changingimmigration-policies.html

Alboim, N., Finnie, R. \& Meng, R. (2005). The Discounting of Immigrants' Skills in Canada: Evidence and Policy Recommendations. IRPP Choices, 11:2.

Archer, K. \& Berdahl, L. (2011). Explorations Conducting Empirical Research In Canadian Political Science. Ontario, Toronto: Oxford University Press.

Black, D. (February 15, 2013). Canada's Immigration History One of Discrimination and Exclusion. Toronto Star. Retrieved on June 15, 2013 from the URL: http://www.thestar.com/news/immigration/2013/02/15/canadas_immigration history_one_of_discrimination_and_exclusion.html

Canadian Multiculturalism Act (CMA) (1985). Retrieved on June 17, 2013 from the URL: http://laws-lois.justice.gc.ca

Canadian Charter of Rights and Freedoms (CCRF) (1982). Retrieved on June 17, 2013 from the URL: http://laws-lois.justice.gc.ca/eng/const/page-15.html

Citizenship Immigration Canada (2013a). Skilled Workers and Professionals. Retrieved on March 29, 2013 from URL:

http://www.cic.gc.ca/english/immigrate/skilled/index.asp

Citizenship Immigration Canada (2013b). News Release- Innovators recognized for work in foreign credential Recognition. Retrieved on March 23, 2013 from URL: http://www.cic.gc.ca/english/department/media/releases/2013/2013-0313.asp

Citizenship Immigration Canada (2013b). Recent Immigrant outcomes- 2005 Employment earnings. Retrieved on March 29, 2013 from URL:

http://www.cic.gc.ca/english/resources/research/outcomes/outcomes-2005.asp

Citizenship Immigration Canada (2013c) News Release December 19 2012-An Immigration System that works for Canada. Retrieved on June 15, 2013 from http://www.cic.gc.ca/english/department/media/releases/2012/2012-12-19.asp

Citizenship Immigration Canada (2013d). Part 2: Proposed Changes to the Federal Skilled Worker Program (continued). Retrieved on June 15, 2013 from URL: http://www.cic.gc.ca/english/department/consultations/fswp/adjustements.asp

Citizenship Immigration Canada (2013e). Language Testing- Federal Skilled Workers. Retrieved on June 16, 2013 from URL: http://www.cic.gc.ca/english/immigrate/skilled/language-testing.asp 
Citizenship Immigration Canada (2013f). Part 2: Proposed Changes to the Federal Skilled Worker Program. Retrieved on June 15, 2013, from URL:

http://www.cic.gc.ca/english/department/consultations/fswp/part2.asp

Citizenship Immigration Canada (2013g). Points for work experience -federal skilled workers. Retrieved on June 16, 2013 from URL:

http://www.cic.gc.ca/english/immigrate/skilled/factor-experience.asp

Citizenship Immigration Canada (2013h). Points for experience - federal skilled workers. Retrieved on June 16, 2013 from URL:

http://www.cic.gc.ca/english/immigrate/skilled/factor-education.asp

Citizenship Immigration Canada (2013i). Points for age. Retrieved on June 17, from URL: http://www.cic.gc.ca/english/immigrate/skilled/factor-age.asp

Citizenship Immigration Canada (2013j). Immigration and Ethnocultural Diversity. Retrieved on August 23, 2013, from URL:

http://www12.statcan.gc.ca/nhs-enm/2011/as-sa/99-010-x/99-010-x2011001eng.cfm

Citizenship Immigration Canada (2010). Evaluation of the Federal Skilled Worker Program. Ottawa, Ontario: Citizenship and Immigration Canada.

Gaertner, S. L. \& Dovidio, J. F. (1986). The aversive form of racism. In J. F. Dovidio \& S. L. Gaertner (Eds.), Prejudice, discrimination, and racism (pp. 61-89). Orlando, FL: Academic Press.

Gaertner, S. L. \& Dovidio, J. F. (2004). Aversive Racism. Advances in Experimental Psychology, 36:1-52.

Gilborn, D. (2006). Critical Race Theory and Education: Racism and Anti-Racism on Educational Theory and Praxis. Discourse: Studies in the Cultural Politics of Education, 27(1): 11-32.

Green, A. G. \& Green D. A.(1995). Canadian Immigration Policy: The Effectiveness of the Point System and Other Instruments. The Canadian Journal of Economics, 28 (4): 1006-1041.

Green, A. G. \& Green D. A. (1999). The Economic Goals of Canada's Immigration Policy: Past and Present. Canadian Public Policy, 25 (4): 425-451.

Grenier, G. \& Xue, L. (2011). Canadian Immigrants' Access to a First Job in Their Intended Occupation. Int. Migration \& Integration, 12:275-303.

Griffin, E. (2009). A First Look At Communication Theory. New York, New York: McGraw Hill.

Li, P. (2003). Destination Canada. Ontario, Toronto: Oxford University Press. 
Lowe, J. (2010). Rearranging the Deck Chairs? A critical Examination of Canada's Shifting (IM)Migration Policies. Canada Issues, 25-28.

Mirchandani, K. (2004). Immigrants matter: Canada's social agenda on skill and learning. Convergence, 37: 1, 61-68.

Munro, M. J. (2003). A Primer on Accent Discrimination in the Canadian Context. TESL Canada Journal, 20:2, 38-51.

Oreopoulos, P. (2009). Why Do Skilled Immigrants Struggle in the Labour Market: A Field Experiment with Six Thousand Resumes. Metropolis British Columbia, $1-50$.

Pendakur, K. \& Pendakur, R. (2010). Colour by Numbers: Minority Earnings in Canada 1995 2005. Int. Migration \& Integration, 12:305-329.

Pendakur, K. \& Pendakur, R. (2002). Language as Both Human Capital and Ethnicity. IMR, 36:1, 147-177.

Reitz, J.G. (2005). Tapping Immigrants' Skills: New Directions for Canadian Immigration Policy in the Knowledge Economy. IRPP Choices, 11(1): 2-13.

Sadiq, K. D. (2005). Race, Ethnicity and Immigration in the Workplace: Visible minority experiences and workplace diversity initiatives. Canadian Issues, 6166.

Shinnaoui, D. \& Narchal, R. (2010). Brain Gain to Brain Waste: Individual Biases, Prejudice, and Discounting of Migrant Skills. Int. Migration \& Integration, 11:423-437.

Van Dijk, T. A. (2005). Chapter 18. Critical Discourse Analysis in D. Schiffrin, D. Tannen and H. E. Hamilton (Eds). The Handbook of Discourse Analysis. $(352-371)$. 